\title{
Hip hemiarthroplasty for femoral neck fractures in end-stage renal disease patients on dialysis compared to patients with late-stage chronic kidney disease
}

\author{
Benjamin TK $\underline{\text { Ding }}^{1}$, MRCSEd, MBBS, Abhishek $\underline{\text { Shinde }}^{1}$, MNAMS, Dortho, Kelvin G $\underline{\operatorname{Tan}}^{1}$, MBBS, FRCSEd
}

INTRODUCTION Hip fractures in patients with end-stage renal disease (ESRD) are associated with frequent complications and poorer outcomes. Patients on chronic dialysis are at additional risk of dialysis-related complications such as myocardial infarction and early osteolysis. We analysed the complications and implant survivorship of hemiarthroplasty in patients with femoral neck fractures with late-stage chronic kidney disease with and without preexisting dialysis.

METHODS We conducted a retrospective case-control study of 28 patients with ESRD and 31 patients with chronic kidney disease (CKD) Stages 3-5, who had a total of 62 fractures treated with hemiarthroplasty between 2005 and 2015. The mean age of the patients was 68.33 (50.21-86.45) years. The mean follow-up time of the group was 39 months. Patient demographics, complications, outcomes and follow-up radiographs were analysed for differences.

RESULTS Patient in both groups had statistically similar demographics and comorbidity scores except for a higher incidence of hyperparathyroidism in ESRD patients on chronic dialysis (nine patients vs. zero patients; $p=0.001$ ). These patients were more likely to develop cardiopulmonary complications in the perioperative period (odds ratio [OR] 5.04; $p=0.04$ ) and implant loosening on radiographic analysis (OR 8.75; $p=0.02$ ). The incidence of loosening was higher in patients with hyperparathyroidism (OR 9.80; $p=0.002)$. Cemented techniques, however, did not appear to be significantly associated with intraoperative fractures or loosening.

CONCLUSION Patients with ESRD on chronic dialysis were more likely to develop cardiopulmonary complications and implant loosening after hemiarthroplasty for femoral neck fractures. Hyperparathyroidism should be optimised, as it may prevent loosening. Our study did not show any difference in complications or outcomes for cemented fixation.

Keywords: chronic kidney disease, dialysis, end-stage renal disease, hip arthroplasty

\section{INTRODUCTION}

Chronic kidney disease (CKD), including end-stage renal disease (ESRD), affects about $5 \%$ of the population and is increasing in incidence. ${ }^{(1)}$ Compared to the general population, subjects with ESRD often develop bone mineral disorders and have a higher risk of hip fractures. ${ }^{(2)}$ Mortality rates after hip fractures for patients on haemodialysis have been reported to be as high as $30 \%$ and $64 \%,{ }^{(3-5)}$ and are often associated with perioperative complications.

Arthroplasty has been recommended by several authors as the surgical treatment of choice for femoral neck fractures given the high risk of failure of internal fixation. ${ }^{(6,7)}$ The current literature regarding outcomes of hemiarthroplasty or total hip arthroplasty in patients with chronic renal failure shows contrasting results, with most of the studies involving a small number of subjects. ${ }^{(6,8,9)}$ Prior studies have also reported an increase in medical complications after fixation of hip fractures in ESRD patients, including pneumonia, acute renal failure, stroke and cardiopulmonary complications. ${ }^{(10)}$ The number of surgical complications, such as deep vein thrombosis, deep wound infections, mortality, loosening and dislocations are also increased in patients with $\mathrm{CKD}^{(11,12)}$ and patients with ESRD undergoing dialysis. ${ }^{(13,14)}$
Trauma, anaesthetic drugs and dialysis may produce significant strain for patients who present with hip fracture. Long-term dialysis may also result in $\beta 2$-microglobulin amyloid deposition in and around joints, predisposing patients to potential early osteolysis. ${ }^{(15,16)}$ The purpose of this study was to analyse the effects of dialysis, cementing and hyperparathyroidism on postoperative complications in patients undergoing hip hemiarthroplasties for femoral neck fractures.

\section{METHODS}

Appropriate ethical approval was obtained from our institution's review board before the study was conducted. We searched our institution's computerised database for all arthroplasties performed for hip fracture patients between 2005 and 2015. The inclusion criteria were estimated glomerular filtration rate $(\mathrm{eGFR})<60 \mathrm{~mL} / \mathrm{min} / 1.73 \mathrm{~m}^{2}$ for patients with late-stage CKD (Stage 3-5); and eGFR $<15 \mathrm{~mL} / \mathrm{min} / 1.73 \mathrm{~m}^{2}$ or initiated renal replacement therapy for patients with ESRD. All patients were managed preoperatively and postoperatively by a nephrology team to optimise their medical condition before and after surgery.

A total of 2,796 hip arthroplasties for femoral neck fractures were performed during this period; among these, 35 patients 
were haemodialysis dependent. After excluding seven patients with revision surgeries, we identified 28 patients with 31 hip hemiarthroplasties for the ESRD dialysis group. 31 patients with CKD Stages 3-5 who were not on dialysis, matched by gender, ethnicity and mean age, made up the control group.

Clinical records and serial radiographs of all included patients were evaluated for loosening ${ }^{(17,18)}$ by the two senior authors. Anteroposterior radiographs of both hips were taken routinely on an annual basis or when clinically symptomatic, as indicated. For patients who had died, the last available radiograph was used in the analysis. The position of the femoral component was assessed by utilising reference points on the tip of the greater trochanter and the prosthesis. Subsidence was present when the femoral component was adjudged to have migrated more than $3 \mathrm{~mm}$ or when more than $5^{\circ}$ of varus/valgus displacement was noted. Radiographic endpoints included cemented implants with definite signs of cement loosening, uncemented stems that were classified as having unstable fibrous ingrowth, and displaced implants requiring revision surgery for any reason other than infection.

Statistical analysis was performed using IBM SPSS Statistics version 20.0 (IBM Corp, Armonk, NY, USA). Univariate analysis of proportions between two categorical variables was performed with chi-square test. Data from two independent samples was compared using $t$-test. The generalised linear mixed model (GLMM) procedure was used to fit statistical models for dependent samples. We used odds ratio (OR) measures obtained from the GLMM and assumption of normality about error. The Cox proportional-hazards model and Kaplan-Meier models were used to analyse survival data. Cumulative survival rates for the two groups were compared using the log-rank test. A p-value $<0.05$ was considered significant.

\section{RESULTS}

The demographic profiles, renal function and dialysis profile of both groups of patients are shown in Table I. The mean age of the patients was $68.33(50.21-86.45)$ years. All patients were ambulant prior to surgery. The CKD/ESRD patients on dialysis were of a similar age as the control group (67.68 years vs. 67.97 years; $p=0.913)$. The average body mass index of the CKD/ESRD patients on dialysis was $25.3 \pm 4.2 \mathrm{~kg} / \mathrm{m}^{2}$ compared to $22.6 \pm 4.9 \mathrm{~kg} / \mathrm{m}^{2}$ in the control group. The mean follow-up time of the cohort was 39 months.

The difference in the incidence of diabetes mellitus, hypertension, hyperlipidaemia, ischaemic heart disease, previous cerebrovascular accidents, autoimmune pathologies and corticosteroid usage between both groups was not statistically significant. Patient demographics, site of surgery, Charlson Comorbidity Index and Charlson Age Comorbidity Index were also not significantly different between the two groups. However, dialysis patients with CKD/ESRD had a higher incidence of hyperparathyroidism (nine patients vs. zero patients; $p=0.001$ ).

Patients in the control group had a higher mean creatinine clearance $(21.2 \pm 11.1 \mathrm{~mL} / \mathrm{min}$ vs. $7.6 \pm 2.1 \mathrm{~mL} / \mathrm{min} ; \mathrm{p}<0.001)$ and a lower mean stage of CKD $(4.0 \pm 0.6$ vs. $5.0 \pm 0.0 ; p<0.001)$
Table I. Patient demographics and comorbidities.

\begin{tabular}{|c|c|c|c|}
\hline \multirow[t]{2}{*}{ Variable } & \multicolumn{2}{|c|}{ No./mean \pm SD } & \multirow[t]{2}{*}{ p-value } \\
\hline & $\begin{array}{l}\text { Control } \\
\text { group }\end{array}$ & $\begin{array}{l}\text { Dialysis } \\
\text { group }\end{array}$ & \\
\hline No. of patients & 31 & 28 & \\
\hline No. of hips & 31 & 31 & \\
\hline Gender & & & - \\
\hline Male & 13 & 13 & \\
\hline Female & 18 & 18 & \\
\hline Ethnicity & & & - \\
\hline Chinese & 25 & 25 & \\
\hline Malay & 2 & 2 & \\
\hline Indian & 4 & 4 & \\
\hline $\begin{array}{l}\text { Age at index } \\
\text { operation (yr) }\end{array}$ & $67.97 \pm 9.93$ & $67.68 \pm 10.99$ & 0.913 \\
\hline BMI $\left(\mathbf{k g} / \mathbf{m}^{2}\right)$ & $22.6 \pm 4.9$ & $25.3 \pm 4.2$ & 0.104 \\
\hline Site of surgery & & & 0.445 \\
\hline Right & 18 & 15 & \\
\hline Left & 13 & 16 & \\
\hline \multicolumn{4}{|l|}{ Comorbidity } \\
\hline Diabetes mellitus & 22 & 23 & 0.776 \\
\hline Hypertension & 29 & 31 & 0.151 \\
\hline Hyperlipidaemia & 27 & 30 & 0.162 \\
\hline Ischaemic heart disease & 26 & 28 & 0.449 \\
\hline $\begin{array}{l}\text { Cerebrovascular } \\
\text { accident }\end{array}$ & 8 & 11 & 0.409 \\
\hline Hyperparathyroidism & 0 & 9 & $0.001 *$ \\
\hline $\begin{array}{l}\text { Autoimmune } \\
\text { pathologies }\end{array}$ & 1 & 5 & 0.086 \\
\hline Corticosteroid use & 0 & 1 & 0.313 \\
\hline \multicolumn{4}{|l|}{ Comorbidity score } \\
\hline $\begin{array}{l}\text { Charlson Comorbidity } \\
\text { Index }\end{array}$ & 5.1 & 5.6 & 0.157 \\
\hline $\begin{array}{l}\text { Charlson Age } \\
\text { Comorbidity Index }\end{array}$ & 7.9 & 7.9 & 0.944 \\
\hline \multicolumn{4}{|l|}{ Renal function } \\
\hline $\begin{array}{l}\text { Creatinine } \\
\text { clearance (mL/min) }\end{array}$ & $21.2 \pm 11.1$ & $7.6 \pm 2.1$ & $<0.001^{*}$ \\
\hline CKD stage & $4.0 \pm 0.6$ & $5.0 \pm 0.0$ & $<0.001^{*}$ \\
\hline $\begin{array}{l}\text { Duration of dialysis } \\
\text { before/after index } \\
\text { operation (mth) }\end{array}$ & $20.1 \pm 26.3$ & $49.3 \pm 44.4$ & $0.005^{*}$ \\
\hline Index operation & & & 0.430 \\
\hline Cemented & 13 & 10 & \\
\hline Uncemented & 18 & 21 & \\
\hline
\end{tabular}

${ }^{*} \mathrm{p}<0.05$ is considered statistically significant. BMI: body mass index; CKD: chronic kidney disease; ESRD: end-stage renal disease; SD: standard deviation

compared to CKD/ESRD patients on dialysis. The mean duration of dialysis prior to surgery for CKD/ESRD dialysis patients was 49.3 \pm 44.4 months. The majority of the patients in the control group eventually required dialysis at an average of $20.1 \pm 26.3$ months postoperatively.

The majority of patients developed CKD/ESRD as a result of diabetes mellitus $(n=41)$ or hypertension $(n=15)$. A small number 
of patients ( $n=6$ ) developed ESRD requiring dialysis due to other causes: three from immunoglobulin A nephropathy, one from chronic glomerulonephritis, one from Alport syndrome and one from gout (not shown). 13 patients in the control group and ten patients in the CKD/ESRD dialysis group had cemented hemiarthroplasties, while 18 patients in the control group and 21 patients in the $\mathrm{CKD} / \mathrm{ESRD}$ dialysis group had uncemented hemiarthroplasties. The difference between cemented and uncemented techniques was not statistically significant ( $p=0.430$; Table I).

Perioperative complications in both groups are detailed in Table II. Differences in the incidence of intraoperative fractures, superficial and deep prosthetic joint infections, dislocations, and nerve injuries between the groups were not statistically significant. The dialysis group had a lower incidence of renalrelated complications such as fluid overload and electrolyte abnormalities (OR 0.52 [0.37-0.73]; $p<0.001$ ). However, it had a significantly higher incidence of cardiopulmonary complications
(OR 5.04 [0.98-26.10]; $p=0.04$ ). The control group had one patient with DVT and 11 patients who developed pneumonia, urinary tract infections or sepsis. The difference between both groups for DVT and infections from other sources was not statistically significant ( $p=0.31$ and 0.79 , respectively). The dialysis group had a higher incidence of radiographic evidence of loosening (OR 8.75 [1.01-76.10]; $p=0.02$ ), but only one of the patients underwent revision surgery for loosening associated with periprosthetic infection. Three of the patients in the control group underwent revision surgery for prosthetic infection and periprosthetic fracture. There were 11 deaths in the control group and seven in the dialysis group within 12 months postoperatively. The average length of hospital stay was $25.7 \pm 27.6$ days in the control group, as compared to $28.1 \pm 21.1$ days in CKD/ESRD dialysis patients $(p=0.71)$.

Cemented and cementless techniques were not associated with intraoperative fractures or loosening (Table III). Two out of

Table II. Relationship between dialysis and perioperative complications.

\begin{tabular}{|c|c|c|c|c|}
\hline \multirow[t]{2}{*}{ Parameter } & \multicolumn{2}{|c|}{ No./mean \pm SD } & \multirow[t]{2}{*}{ OR $(95 \% \mathrm{Cl})$} & \multirow[t]{2}{*}{ p-value } \\
\hline & Control group & Dialysis group & & \\
\hline \multicolumn{5}{|l|}{ Surgical } \\
\hline Intraoperative fracture & 2 & 4 & $2.15(0.36-12.70)$ & 0.39 \\
\hline Superficial skin infection & 4 & 2 & $0.47(0.08-2.75)$ & 0.39 \\
\hline Prosthetic joint infection & 2 & 2 & $1.00(0.13-7.59)$ & 1.00 \\
\hline latrogenic nerve injury & 0 & 1 & $1.03(0.97-1.10)$ & 0.31 \\
\hline \multicolumn{5}{|l|}{ Medical } \\
\hline Deep vein thrombosis & 1 & 0 & $0.97(0.91-1.03)$ & 0.31 \\
\hline Pneumonia/UTI/sepsis & 11 & 10 & $0.87(0.30-2.48)$ & 0.79 \\
\hline Cardiopulmonary complication & 2 & 8 & $5.04(0.98-26.10)$ & $0.04^{*}$ \\
\hline \multicolumn{5}{|l|}{ Long-term complication } \\
\hline Radiographic loosening & 1 & 7 & $8.75(1.01-76.10)$ & $0.02^{*}$ \\
\hline Reoperation/revision & 3 & 1 & $0.31(0.03-3.17)$ & 0.30 \\
\hline SICU stay/intubation & 2 & 3 & $1.55(0.24-10.00)$ & 0.64 \\
\hline 12-mth mortality & 11 & 7 & $0.53(0.17-1.62)$ & 0.26 \\
\hline Length of hospital stay (day) & $25.7 \pm 27.6$ & $28.1 \pm 21.1$ & - & 0.71 \\
\hline
\end{tabular}

${ }^{*} p<0.05$ is considered statistically significant. Cl: confidence interval; CKD: chronic kidney disease; OR: odds ratio; SD: standard deviation; SICU: surgical intensive care unit; UTI: urinary tract infection

Table III. Relationship between cementing and postoperative complications.

\begin{tabular}{|c|c|c|c|c|}
\hline \multirow[t]{2}{*}{ Parameter } & \multicolumn{2}{|c|}{ No./total } & \multirow[t]{2}{*}{ OR $(95 \% \mathrm{Cl})$} & \multirow[t]{2}{*}{ p-value } \\
\hline & Cemented & Uncemented & & \\
\hline \multicolumn{5}{|l|}{ All patients } \\
\hline Intraoperative fracture & $2 / 21$ & $4 / 35$ & $1.20(0.20-7.12)$ & 0.841 \\
\hline Radiographic loosening & $2 / 21$ & $6 / 33$ & $1.90(0.35-10.4)$ & 0.448 \\
\hline \multicolumn{5}{|l|}{ Control group } \\
\hline Radiographic loosening & $0 / 13$ & $1 / 17$ & $1.06(0.95-1.18)$ & 0.391 \\
\hline \multicolumn{5}{|l|}{ Dialysis group } \\
\hline Intraoperative fracture & $1 / 9$ & $3 / 18$ & $1.50(0.14-16.5)$ & 0.739 \\
\hline Radiographic loosening & $2 / 8$ & $5 / 16$ & $1.25(0.20-7.92)$ & 0.813 \\
\hline
\end{tabular}

$\mathrm{Cl}$ : confidence interval; OR: odds ratio 
21 cemented hips and four out of 35 uncemented hips developed intraoperative fractures $(p=0.841)$. Two out of 21 cemented hips, and six out of 33 uncemented hips developed radiographic evidence of loosening $(p=0.448)$. In a subgroup analysis, among the control group, one out of 12 patients with cemented hemiarthroplasty and one out of 17 patients with uncemented hemiarthroplasty developed intraoperative fracture $(p=0.812)$. In the control group, one out of 17 patients with uncemented hemiarthroplasty and none of the patients with cemented hemiarthroplasty experienced loosening $(p=0.391)$. In the ESRD dialysis group, one out of nine patients in the cemented group and three out of 18 patients in the uncemented group had intraoperative fractures $(p=0.739)$. Two out of eight patients in the cemented hemiarthroplasty group developed radiographic loosening, while five out of 16 developed loosening in the uncemented hemiarthroplasty group $(p=0.813)$.

All patients with hyperparathyroidism had serum parathyroid levels $>10 \mathrm{pmol} / \mathrm{L}$ and had their calcium and phosphate levels managed by renal physicians using dialysis, calcium supplements or lanthanum carbonate. Three patients were on cinacalcet treatment and none of the patients were on

Table IV. Relationship between hyperparathyroidism (HPT) and postoperative complications.

\begin{tabular}{|c|c|c|c|c|}
\hline \multirow[t]{2}{*}{ Parameter } & \multicolumn{2}{|c|}{ No./total } & \multirow[t]{2}{*}{ OR $(95 \% \mathrm{Cl})$} & \multirow[t]{2}{*}{ p-value } \\
\hline & HPT & No HPT & & \\
\hline \multicolumn{5}{|l|}{ All patients } \\
\hline $\begin{array}{l}\text { Intraoperative } \\
\text { fracture }\end{array}$ & $2 / 7$ & $4 / 49$ & $3.50(0.54-22.8)$ & 0.169 \\
\hline $\begin{array}{l}\text { Radiographic } \\
\text { loosening }\end{array}$ & $4 / 5$ & $4 / 49$ & $9.80(1.86-51.7)$ & $0.002^{*}$ \\
\hline \multicolumn{5}{|l|}{ Control group } \\
\hline $\begin{array}{l}\text { Intraoperative } \\
\text { fracture }\end{array}$ & $2 / 7$ & $3 / 20$ & $2.86(0.34-24.3)$ & 0.322 \\
\hline $\begin{array}{l}\text { Radiographic } \\
\text { loosening }\end{array}$ & $4 / 5$ & $3 / 19$ & $5.07(0.84-30.4)$ & 0.063 \\
\hline \multicolumn{5}{|l|}{ Dialysis group } \\
\hline $\begin{array}{l}\text { Intraoperative } \\
\text { fracture }\end{array}$ & $1 / 9$ & $3 / 18$ & $1.50(0.14-16.5)$ & 0.739 \\
\hline $\begin{array}{l}\text { Radiographic } \\
\text { loosening }\end{array}$ & $2 / 8$ & $5 / 16$ & $1.25(0.20-7.92)$ & 0.813 \\
\hline
\end{tabular}

${ }^{*} p<0.05$ is considered statistically significant. Cl: confidence interval; ESRD: end-stage renal disease; OR: odds ratio bisphosphonate therapy or had undergone parathyroidectomy at the time of surgery. Hyperparathyroidism was not associated with intraoperative fractures $(p=0.169)$, but was associated with increased rates of radiographic loosening when compared among all patients (OR 9.80; $p=0.002$ ). Among 31 CKD/ESRD patients who were not undergoing dialysis, four patients with hyperparathyroidism and three without hyperparathyroidism developed loosening. The odds ratio of loosening in control patients with hyperparathyroidism was 5.07 ( $p=0.063$; Table IV).

All patients with intraoperative fractures had Dorr Type C femurs. ${ }^{(19)}$ The details of patients with intraoperative fractures are shown in Table V. Two fractures occurred at the greater trochanter and four at the lesser trochanter. Fractures were fixed using trochanteric plates, long stem implants or cerclage wiring. Only one intraoperative fracture progressed to prosthetic loosening at 30 months.

The details of patients with prosthetic loosening are shown in Table VI. Among the eight patients who had migrated protheses, the average time to loosening of the hip prosthesis was 31.6 months. Half of the patients had hyperparathyroidism and three-quarters had uncemented hip bipolar hemiarthroplasties. Only one patient underwent revision total hip replacement, while the others were asymptomatic or had significant comorbidities and were conservatively managed.

Cumulative survival with death as an endpoint at one year was $77.4 \%$ (confidence interval [Cl] 65\%-93\%) and 64.5\% (Cl 64\%$112 \%$ ) in the preoperatively dialysed patients and control group, respectively. The relative risk of 12 -month mortality in the dialysis group was $0.55(\mathrm{Cl} 0.17-1.77 ; \mathrm{p}=0.31)$. Cumulative survival with death as an endpoint at five years was $42.3 \%(\mathrm{Cl} 41 \%-88 \%)$ and $45.2 \%$ (Cl 38\%-68\%) in the preoperatively dialysed patients and the control group patients, respectively $(p=0.24)$. Cumulative survival with migration as an endpoint at five years was $62.4 \%$ (Cl 14\%-141\%) and $87.5 \%(\mathrm{Cl} 49 \%-97 \%)$ among the surviving patients who were preoperatively dialysed and those in the control group, respectively $(p=0.04)$.

\section{DISCUSSION}

Patients with ESRD are a challenging group, as they have higher postoperative morbidity and mortality after surgery for hip fractures. ${ }^{(3-5)}$ The increased risk of complications and mortality may be due to the ESRD, complications of dialysis,

Table V. Details of patients from both groups with intraoperative fractures.

\begin{tabular}{|c|c|c|c|c|c|c|c|c|}
\hline No. & $\begin{array}{l}\text { Gender, age at } \\
\text { surgery (yr) }\end{array}$ & $\begin{array}{l}\text { Duration of } \\
\text { dialysis (mth) }\end{array}$ & $\begin{array}{l}\text { Dorr } \\
\text { type }\end{array}$ & Cementation & HPT & Type of fracture & Treatment & Loosening \\
\hline 1 & Male, 66 & - & $\mathrm{C}$ & Cemented & No & Greater trochanter & $\begin{array}{l}\text { Trochanteric plate and } \\
\text { cerclage wiring }\end{array}$ & No \\
\hline 2 & Male, 63 & - & C & Cemented & No & Lesser trochanter & Cerclage wiring & No \\
\hline 3 & Female, 53 & 60 & C & Uncemented & Yes & Lesser trochanter & Cerclage wiring & No \\
\hline 4 & Female, 72 & 76 & $\mathrm{C}$ & Uncemented & Yes & Greater trochanter & $\begin{array}{l}\text { Long stem implant and } \\
\text { cerclage wiring }\end{array}$ & No \\
\hline 5 & Female, 52 & 82 & C & Uncemented & No & Lesser trochanter & Cerclage wiring & No \\
\hline 6 & Male, 50 & 1 & $\mathrm{C}$ & Uncemented & No & Lesser trochanter & Cerclage wiring & Yes, in $30 \mathrm{mth}$ \\
\hline
\end{tabular}

HPT: hyperparathyroidism; NA: not applicable 
Table VI. Details of migrated prostheses in patients from both groups.

\begin{tabular}{|lllllll|}
\hline No. & $\begin{array}{l}\text { Gender, age at } \\
\text { surgery }(\mathbf{y r})\end{array}$ & $\begin{array}{l}\text { Duration of } \\
\text { dialysis }(\mathbf{m} \mathbf{t h})\end{array}$ & HPT & Cementation & $\begin{array}{l}\text { Time to } \\
\text { migration }(\mathbf{m t h})\end{array}$ & Treatment \\
\hline 1 & Female, 67 & - & No & Uncemented & 24 & 1-stage revision THR \\
\hline 2 & Male, 53 & 42 & Yes $(>220 \mathrm{pmol} / \mathrm{L})$ & Cemented & 36 & Conservatively managed \\
\hline 3 & Female, 62 & 140 & Yes $(>220 \mathrm{pmol} / \mathrm{L})$ & Uncemented & 36 & Conservatively managed \\
\hline 4 & Female, 62 & 140 & No & Uncemented & 72 & Conservatively managed \\
\hline 5 & Female, 54 & 16 & No & Uncemented & 30 & Conservatively managed \\
\hline 6 & Male, 50 & 1 & Yes $(>220 \mathrm{pmol} / \mathrm{L})$ & Uncemented & 30 & Bedbound due to other comorbidities \\
\hline 7 & Female, 55 & 77 & Yes $(52.3 \mathrm{pmol} / \mathrm{L})$ & Uncemented & 24 & Conservatively managed \\
\hline 8 & Male, 53 & 175 & & & & Wheelchair-bound due to other \\
& & & & & & \\
\hline
\end{tabular}

HPT: hyperparathyroidism; THR: total hip replacement

fluid and electrolyte imbalances, and pre-existing cardiovascular occlusions. Despite the high risk of complications, arthroplasty of femoral neck fractures is recommended in displaced femoral neck fractures in lieu of the greater complications associated with conservative management. ${ }^{(20,21)}$

We aimed to assess the clinical outcomes of surgically treated hip fractures in patients undergoing chronic dialysis by comparing them against patients with similar renal and cardiovascular function who were not undergoing dialysis. Our study showed that the patients undergoing dialysis had decreased odds of renal-related complications. This suggests that patients on chronic dialysis were better able to control their fluid and electrolyte balances by calibration of dialysis ultrafiltrate prior to and after their operation. Patients with ESRD who were not on dialysis were, however, less able to regulate their renal function perioperatively and should be considered for initiation of early dialysis to prevent such complications.

The patients undergoing chronic dialysis had increased odds of cardiopulmonary complications, including acute pulmonary oedema, myocardial infarctions and malignant arrhythmias. The results are similar to other studies ${ }^{(22)}$ and may be due to blood pressure and electrolyte fluctuations during the post-traumatic phase, the anaesthetic drugs, and the dialysis itself.

The odds of radiographic loosening of the implants was significantly higher in the dialysis group, with a significantly lower five-year cumulative prosthesis survival rate among surviving patients. Our results show better outcomes compared to previous studies by Blacha et $\mathrm{al}^{(23)}$ in which the cumulative survival for prosthesis migration was $44 \%$ (of 26 bipolar hemiarthroplasties) at five years, and Toomey and Toomey, ${ }^{(24)}$ in which eight out of 15 cemented stems migrated with a mean time-to-failure of eight years. The increased incidence of $\beta 2$-microglobulin amyloidosis in chronic dialysis patients ${ }^{(15,16)}$ has been suggested as one of the causes of loosening. ${ }^{(25)}$ This, coupled with the increased incidence of hypotension and hyperparathyroidism, may result in metabolic bone disorders and decreased mineralisation. In the present study, four patients underwent parathyroidectomy and all patients had their calcium and phosphate levels closely monitored by renal physicians, which may have explained the slightly better cumulative prosthesis survival rate.
Parathyroid hormone (PTH) consists of a chain of 84 amino acids and is a major regulator of bone metabolism and calcium homeostasis, acting on bone, the kidneys and the gastrointestinal tract via a negative feedback loop. ${ }^{(26,27)}$ It has both catabolic and anabolic effects on bone, resulting in what is known as the PTH paradox; continuous infusions of PTH result in bony resorption and a net catabolic effect, while intermittent exposure can lead to dramatic increases in bone regeneration and bone volume. ${ }^{(28,29)}$ Implant osseointegration is a complex process that involves not just osteogenesis but osteoinduction, osteoconduction and remodelling of the bone to provide both osseointegration and mechanical fixation. ${ }^{(26,30-32)}$ Patients with ESRD encounter multiple barriers to osseointegration, including imbalances in calcium and phosphate homeostasis, vitamin D deficiencies, malnutrition, and limitations in mobility, leading to reduced stress loading required for bone remodelling. While vitamin D has been shown to lower PTH levels and improve implant fixation in animal models, ${ }^{(33-36)}$ the direct effect of PTH on osseointegration in CKD/ESRD patients has not been well evaluated previously and requires further study.

While the incidence of loosening appears to be higher in patients with CKD/ESRD on dialysis, the usage of cemented hemiarthroplasties does not appear to reduce the risk of loosening. This may be likely due to selection bias, as patients with poorer bone quality and metabolic bone diseases are more likely to undergo cemented hemiarthroplasty. This may account for the slightly increased number of intraoperative fractures in the cemented group. Hyperparathyroidism is associated with increased odds of developing radiographic loosening. Medical management of hyperparathyroidism appears inadequate, and we recommend optimising hyperparathyroidism management surgically in the same setting if possible to reduce the risk of loosening.

We acknowledge a few limitations to our study. Its retrospective nature and small numbers do not permit firm conclusions, and larger, prospective, long-term studies are warranted. However the inherently small numbers of this group of patients with limited life expectancy restrict the conduct of large-scale, prospective, long-term studies. Furthermore, the surgeries were performed by multiple surgeons with different surgical techniques and implants, as well as varying postoperative 
rehabilitation protocols. The lack of uniformity may skew results but allows for generalisation to a heterogeneous population.

In conclusion, ESRD patients on chronic dialysis and CKD/ ESRD patients without dialysis who undergo hemiarthroplasty for femoral neck fractures are associated with a high risk of complications and mortality. These patients require closer monitoring of their cardiopulmonary and renal function, respectively, as there appears to be a greater incidence of these complications. Patients on chronic dialysis appear to have an increased incidence of implant loosening and should receive extended follow-up for radiological assessment of their implants. Cemented or uncemented hemiarthroplasties do not appear to decrease the rates of loosening. We recommend optimising hyperparathyroidism management surgically to reduce the risk of loosening.

\section{REFERENCES}

1. Levey AS, Beto JA, Coronado BE, et al. Controlling the epidemic of cardiovascular disease in chronic renal disease: what do we know? What do we need to learn? Where do we go from here? National Kidney Foundation Task Force on Cardiovascular Disease. Am J Kidney Dis 1998; 32:853-906.

2. Jadoul M, Albert JM, Akiba T, et al. Incidence and risk factors for hip or other bone fractures among haemodialysis patients in the Dialysis Outcomes and Practice Patterns Study. Kidney Dis 2006; 70:1358-66.

3. Beaubrun AC, Kilpatrick RD, Freburger JK, et al. Temporal trends in fracture rates and post discharge outcomes among hemodialysis patients. J Am Soc Nephrol 2013; 24:1461-9.

4. Mittalhenkle A, Gillen DL, Stehman-Breen CO. Increased risk of mortality associated with hip fracture in the dialysis population. Am J Kidney Dis 2004; 44:672-9.

5. Tentori F, McCullough K, Kilpatrick RD, et al. High rates of death and hospitalization follow bone fracture among hemodialysis patients. Kidney Int 2014; 85:166-73.

6. Hardy P, Benoit J, Donneaud B, Jehanno P, Lortat-Jacob A. [Pathological fractures of the femoral neck in hemodialyzed patients. Apropos of 26 cases]. Rev Chir Orthop Reparatice Appar Mot 1994; 80:702-10. French.

7. Kalra S, McBryde CW, Lawrence T. Intracapsular hip fractures in end-stage renal failure. Injury 2006; 37:175-84.

8. Karaeminogullari O, Demirors $\mathrm{H}$, Sahin O, et al. Analysis of outcomes for surgically treated hip fractures in patients undergoing chronic hemodialysis. J Bone Joint Surg Am 2007; 89:324-31.

9. Sakabe T, Imai $\mathrm{R}$, Murata $\mathrm{H}$, et al. Life expectancy and functional prognosis after femoral neck fractures in hemodialysis patients. J Orthop Trauma 2006; 20:330-6

10. Lin JC, Liang WM. Mortality and complications after hip fracture among elderly patients undergoing hemodialysis. BMC Nephrol 2015; 16:100.

11. McCleery MA, Leach WJ, Norwood T. Rates of infection and revision in patients with renal disease undergoing total knee replacement in Scotland. J Bone Joint Surg Br 2010; 92:1535-9.

12. Deo $\mathrm{S}$, Gibbons $\mathrm{CL}$, Emerton $\mathrm{M}$, Simpson $\mathrm{AH}$. Total hip replacement in renal transplant patients. J Bone Joint Surg Br 1995; 77:299-302.
13. Sakalkale DP, Hozack WJ, Rothman RH. Total hip arthroplasty in patients on long-term renal dialysis. J Arthroplasty 1999; 14:571-5

14. Sunday JM, Guille JT, Torg JS. Complications of joint arthroplasty in patients with end-stage renal disease on hemodialysis. Clin Orthop Relat Res 2002; (397):350-5.

15. Crawford R, Athanasou NA. Beta 2-microglobulin amyloid deposition in hip revision arthroplasty tissues. Histopathology 1998; 33:479-84.

16. Gejyo F, Yamada T, Odani S, et al. A new form of amyloid protein associated with chronic hemodialysis was identified as beta 2-microglobulin. Biochem Biophys Res Commun 1985; 129:701-6.

17. Engh CA, Glassman AH, Griffin WL, Mayer JG. Results of cementless revision for failed cemented total hip arthroplasty. Clin Orthop Relat Res 1988; (235):91-110.

18. Harris WH, McCarthy JC Jr, O'Neill DA. Femoral component loosening using contemporary techniques of femoral cement fixation. J Bone Joint Surg Am 1982; 64:1063-7.

19. Dorr LD, Faugere MC, Mackel AM, et al. Structural and cellular assessment of bone quality of proximal femur. Bone 1993; 14:231-42.

20. Tzamaloukas AH, Murphy G, Schaab PC, Worrel RV. Conservative versus operative management of femoral neck fractures in patients on long-term dialysis. Nephron 1990; 55:229-30.

21. Nikkel LE. Moving beyond hip fracture risk assessment for patients on dialysis. Kidney Int Rep 2018; 3:1253-4.

22. Cherng YG, Liao CC, Chen TH, et al. Are non-cardiac surgeries safe for dialysis patients? - A population-based retrospective cohort study. PLoS One 2013; 8:e58942.

23. Blacha J, Kolodziej R, Karwanski M. Bipolar cemented hip hemiarthroplasty in patients with femoral neck fracture who are on hemodialysis is associated with risk of stem migration. Acta Orthop 2009; 80:174-8.

24. Toomey HE, Toomey SD. Hip arthroplasty in chronic dialysis patients. J Arthroplasty 1998; 13:647-52.

25. Umeda N, Saito M, Miki H, et al. Failed hip prostheses in hemodialysis patients. Amyloid deposition at the bone-implant interface in 4 cases. Acta Orthop Scand 1998; 69:14-6.

26. Daugaard $\mathrm{H}$. The influence of parathyroid hormone treatment on implant fixation. Dan Med Bull 2011; 58:B4317.

27. Arnaud CD Jr, Tenenhouse AM, Rasmussen H. Parathyroid hormone. Ann Rev Physiol 1967; 29:349-72.

28. Qin L, Raggatt LJ, Partridge NC. Parathyroid hormone: a double-edged sword for bone metabolism. Trends Endocrinol Metab 2004; 15:60-5.

29. Miyakoshi N. [Morphological analysis of bone dynamics and metabolic bone disease. Effects of parathyroid hormone on bone tissue]. Clin Calcium 2011; 21:575-81. Japanese.

30. Albrektsson TO, Johansson CB, Sennerby L. Biological aspects of implant dentistry: osseointegration. Periodontol 2000 1994; 4:58-73.

31. Albrektsson T, Brånemark Pl, Hansson HA, Lindström J. Osseointegrated titanium implants. Requirements for ensuring a long-lasting, direct bone-to-implant anchorage in man. Acta Orthop Scand 1981; 52:155-70.

32. Albrektsson T, Johansson C. Osteoinduction, osteoconduction and osseointegration. Eur Spine J 2001; 10 Suppl 2:S96-101.

33. Liu W, Zhang S, Zhao D, et al. Vitamin D supplementation enhances the fixation of titanium implants in chronic kidney disease mice. PLoS One 2014; 9:e95689.

34. Kandula P, Dobre M, Schold JD, et al. Vitamin D supplementation in chronic kidney disease: a systematic review and meta-analysis of observational studies and randomized controlled trials. Clin J Am Soc Nephrol 2011; 6:50-62.

35. Zhou C, Li Y, Wang X, Shui X, Hu J. 1,25Dihydroxy vitamin D(3) improves titanium implant osseointegration in osteoporotic rats. Oral Surg Oral Med Oral Pathol Oral Radiol 2012; 114(5 Suppl):S174-8.

36. Dvorak G, Fügl A, Watzek G, et al. Impact of dietary vitamin D on osseointegration in the ovariectomized rat. Clin Oral Implants Res 2012; 23:1308-13. 